\title{
Roles of a Case Library as a Collaborative Tool for Fostering Argumentation
}

\author{
Janet L. Kolodner*, Baruch Schwarz**, Reuma DeGroot Barkai**, Edith Levy- \\ Neumand ${ }^{* *}$, Anna Tcherni**, and Anat Turbovsky** \\ *Edutech Institude, College of Computing, Georgia Institute of Technology \\ **School of Education, Hebrew University
}

\begin{abstract}
We tried to create an environment conducive to learning argumentation skills by combining collaborative use of case libraries with teacher facilitation of an appropriate kind. We present here the way we designed the environment, including the case library we created and the role of the teacher. The role of the case library in facilitating both collaboration and construction and evaluation of arguments is analyzed through examples. While preliminary, our analysis suggests (i) several principles for designing a case library as an invitation to interpretation and (ii) that integration of such a tool into the classroom provides a viable way of supporting creation of better arguments, learning of argumentation norms, and conflict resolution and negotiations among students.
\end{abstract}

Keywords-argumentation, case-based reasoning, case library, middle school, tools to support collaborative learning

\subsection{Introduction}

Informal reasoning involves generating or evaluating (or both) evidence pertaining to a claim or conclusion. It is most useful when information that is available doesn't point toward a single consistent conclusion (Means \& Voss, 1996), and at its core is the generation and evaluation of arguments. Educating students to argue well is essential (e.g., Voss, Perkins \& Segal, 1991). But setting up a learning environment well to facilitate such learning is difficult. If a teacher intercedes too much, for example, his biases are interjected into student arguments, or alternatively, his intercessions are seen by students as prescriptions for what they need to do - the opposite of what needs to be taught.

We tried to create an environment conducive to learning argumentation skills by combining collaborative use of case libraries with teacher facilitation of an appropriate kind. We present here the way we designed such an environment, including the case library we created and the role of the teacher. The role of the case library in facilitating both collaboration and construction and evaluation of arguments is analyzed through examples. While preliminary, our analysis suggests (i) principles for designing a case library as an invitation to interpretation and (ii) that integration of such a tool into the classroom provides a viable way to scaffold creation of better arguments, learning of argumentation norms, and conflict resolution and negotiations among students.

\subsection{Education to Argumentation}

It seems reasonable to hypothesize that argumentation skills will best be cultivated in a collaborative educational setting, one in which students have a chance to hear expert arguments and analyze them for their essential features, engage in argumentation on a regular basis, and critique their arguments, gradually learning the skills required. But educating for good argumentation skills cannot easily adopt any of the popular educational models based on an asymmetric relation expert-novice relation between teacher and student (e.g., cognitive apprenticeship (Collins, Brown \& Newman, 1989)). One reason is that modeling argumentation requires exemplary discussion between two or more expert arguers. It can hardly be modeled by one person. Second, a scaffolding-like stage is difficult to adapt from those models. Any authoritarian intervention modifies argumentation in a way that may be lethal for it, because authority biases debates. Moreover, the teacher needs to intervene very cautiously, taking into account the current arguments of the participants and a plan for modifying their argumentation without impairing engagement. Finally, prompting during argumentative talk moves the talk to an adultcontrolled activity, with the risk that student focus will move from content to form.

We therefore adopt an emergent perspective for our curriculum and software design (Yackel \& Cobb, 
1996), taking instruction from the precursory attempts of Roschelle (1992) and Schwarz (1997). Each analyzed interactions between students who worked in pairs to learn concepts in physics (Roschelle) or mathematics (Schwarz) using a software tool that focused their discussions and allowed them to explore their conjectures. The Roschelle and Schwarz studies showed that collaborative use of representational and exploratory tools can aid understanding and acquisition of concepts by serving as communicative tools for constructing social and cognitive entities. We investigated whether a non-authoritarian computer tool that would suggest to students many alternatives without bothering their train of thought would help them to construct good arguments, use evidence well and avoid bias, and help them to become good arguers. We designed a special case library (Kolodner, 1993, 1997) for this purpose.

\subsection{The Case Library}

A case library has two major parts to it (Kolodner, 1993): its cases (the content of the case library), and its indexes (the access it provides to its cases). A case represents an experienced situation, something that happened. It has several parts: (i) the problem or situation that it is about, (ii) the means of addressing the problem or navigating the situation, (iii) what happened as a result of carrying out that solution or activity, and (iv) if possible, an explanation of why it might or might not have come out as expected.

One can thus think of a case library as a wellorganized hypertext resource, where the heart of the resource is its cases. But a case library can have other resources in it as well, e.g., background or contextual information about its issues and cases, detailed technical information about its cases, explanations derived from cases, and connections between its cases. Research in case-based reasoning shows that the more complete each of the four parts of a case is, the better the connections between its parts, and the better its background, contextual information, and technical information, the more useful a case will be in aiding reasoning (Kolodner, 1993).

While solving a problem or reasoning, a reasoner navigates to appropriate cases in the case library by using its indexed links. A case, told as a story about what happened in some situation, may suggest a way to solve a new problem, an issue that needs to be addressed, or a problem that might be expected to arise if some type of solution is put in place. An example will provide some concreteness.

Our students were working on the issue of how to solve traffic congestion problems in Israel. Several years ago, the government decided to solve traffic problems by building a new highway to connect northern and central portions of Israel to each other. But recently, environmentalists, some government officials, and the populace have been questioning whether building this road is a good idea. Those opposed to the road are aiming to have the decision overturned before the government begins allocating large amounts of money to building the road. We asked students to decide where they stood on the issue and to present a convincing argument on behalf of their opinion.

A relevant case for anyone considering this issue is one about road-building in Atlanta, GA. In Atlanta, a perimeter highway was built about two decades ago to relieve traffic congestion. This made outlying regions more accessible, and more people moved to them and to Atlanta, improving its economy. But that brought more cars as well, and many years later there is more traffic congestion than before; but this time involving more cars and creating more pollution. Roads have been widened and new roads built to take care of this, but the congestion comes back quickly and pollution is increasing.

The story above connects the outcome of building the highway (continued congestion; more cars; more pollution) with the reasons for that outcome (outlying areas were made more accessible). A reasoner seeing this case might be prompted to look into the effects of more roads on pollution, on the economics of a region, on relocation, on traffic congestion, and so on. As well, this case provides some evidence to justify increased pollution and recurring traffic congestion should Israel build its proposed highway.

\subsection{Content and Organization}

Cases in the case library we designed are presented as texts and graphics extracted from newspaper and magazine articles. An attempt was made to be as complete as possible in describing each. But there was also an attempt to make texts as brief, interesting, and readable as possible so students wouldn't feel like they were drowning in text and to support texts with as much visual material as possible. Cases represent attempts made around the world to deal with traffic congestion. The case library has examples of putting in better public transportation systems, helping people change their traveling habits, and building more roads. Each case was written as a story that told what the problem was and a bit about its context, what was done to deal with it, and what happened as a result.

Each text is linked to background information, such as definitions of terms and concepts (e.g., pollution), to texts showing cases that present similar evidence, to cases presenting opposing evidence, and to predictions relating to the particular concern or solution chosen. Such links embody the fact that the case library is a tool for argumentation: Possible sources of information are accessible, evidence is 
provided, and alternatives are proposed. The case library includes examples and facts that are usable as evidence in arguments about whether or not to build the highway through Israel.

But content is not the only thing important in a case library. As in a traditional library, it is also necessary to be able to access those contents easily. The case library's indexing and browsing systems allow that. Browsing allows an overall view of what is in a library (as one when focuses in some area of a library looking at what is on the shelves). Indexing allows access to items focusing on particular topics (as a card catalog does in a physical library).

The case library we designed allows access in several different ways:

- $\quad$ Each case is indexed by the kind of solution it implemented -- public transportation systems, change of habits of commuters, building roads.

- $\quad$ Each case is also indexed by the set of issues it addressed, e.g., pollution, economics.

- Cases and other content are cross-indexed several ways. Each issue has background information associated with it that is accessible along with the cases about that issue. And each case has associated with it other cases that are similar and others that are opposed.

The interface makes it easy to see the range of solutions included and the range of issues others had addressed in similar situations, and users can browse the library or focus in on particular topics.

\subsection{Design of the Case Library: Principles Used}

The case library was designed and constructed by the last four authors, all students in Kolodner's class on Cognition, Computation, and Education, in collaboration with Kolodner and Schwarz. One of the designers was the teacher of these students (Barkai), and all are members of Schwarz' curriculum design team. Design of the case library was based on several principles. The intent was that the case library would act as an external memory tool for promoting the construction of internal representations. Our plan was for students to access the case library as a resource as they were constructing their arguments. Our expectations were that students would browse the case library looking for the kinds of issues they needed to address, that they would choose issues to address and find cases centered around those cases, and that after reading a relevant case from the case library, they would be able to use its suggestions in approaching their argument.

But we also wanted them to internalize representations that promote good argumentation.
This required that it be more than an expert resource. In particular, we wanted its design to invite students to interpret its contents in ways that would lead to good understanding of what a good argument is and good argumentation skills.

Designing with such a principle in mind requires us to specify what students need to wonder about and make sense of to be good arguers. It also asks us to figure out how we can get them to wonder about arguments, their evaluation and alternatives. We knew we needed to keep in mind both what students needed to be learning and what difficulties they might have both in carrying out their tasks and in learning. We took our cues from other case libraries built for education and from the roles other tools have played in collaborative learning. Our intent was that the case library play three roles for the students:

- It would be a resource, providing them with facts, predictions, and information about dilemmas and alternative solutions. This is its traditional role in helping novices and experts alike (Kolodner, 1993; Domeshek \& Kolodner, 1992; Ferguson et al, 1993).

- It would scaffold and mediate construction of arguments. Using its cases, students would find examples that would help them formulate assertions. Other examples, predictions, and background information would serve as evidence. Its organizational structure and menus of indexing terms would suggest to students issues they should address to make a good argument. Student arguments would be better than if they had used no tool or some other set of resources that was not purposely structured to suggest issues to address. This role for case libraries has been implemented in several case-based learning aids built for student designers (Narayanan et al, 1995).

- It would serve as a catalyst for collaborative learning, providing students with topics to talk about and ideas about how to move forward, concretely presented. Its role here was to be a collaborator in the group, though one with limited powers -- it could actively make a broad range of suggestions when asked, passively give hints if students paid attention to it, and provide information that might suggest ways out of collaboration dilemmas.

To know how to organize (index) the resources, to decide which resources were needed, and to decide which things the students needed to discuss, we examined the tasks students would be involved in, the important decisions that must be made to engage in that task, which skills the children needed to learn to 
do this, the resources they needed, and which things might be difficult. Our design was guided by this analysis. Several examples illustrate:

- Justifying an assertion requires resources that provide evidence (e.g., examples, predictions made by others, facts/background information). The case library includes this type of information.

- Work the children were already doing showed us that the were having trouble with the idea of examining alternative solutions. They tended to focus on whatever solution they came up with and try to justify it rather than considering alternatives. We thus made sure that the system made clear when several alternative solutions were possible. We did this in three ways: by indexing by alternative types of solutions to transportation problems, thereby providing for the kids a list of alternatives; by making sure to include alternative solutions to each issue/problem represented in the system; and by cross-indexing cases to others that differed in their approaches to the same problem.

- We also knew that children have trouble generating issues to address. They don't understand how issues and solutions impact each other. We addressed this two ways: (i) Stories concretely specify the range of issues addressed and full spectrum of good and poor outcomes resulting from the solution method employed. This way, reading any story suggests issues that are important to take into account. (ii) Screens are designed to make issues clear: the list of issues used to index cases are listed on the screen, suggesting issues students might usefully explore in addition to those they had thought of themselves.

All this is presented in a way that invites interpretations. The closeness or differences between cases, for example, is not clearly specified; students must analyze similarities and differences between cases to construct a good argument. Students needed to decide which issues to focus on; we don't tell them which, but the menu of issues that they use to specify which cases they want to see and the issues that come up in the cases themselves suggest relevant issues for focus. Cases and predictions play different roles in justifying a claim; students had to analyze what they found to determine what evidence to use and then synthesize an argument based on those analyses.

\section{The Classroom Environment}

Use of the case library was integrated into a larger curriculum developed by Schwarz and colleagues at the Hebrew University. The aim of the curriculum was to create conditions for the emergence of a culture of argumentation. Students would learn to argue by arguing (i.e., doing), critiquing their arguments as a class and reflecting on them, and then engaging in other argumentation activities. Complexity was added gradually, but the framework for arguing and interacting remained the same across activities, allowing students to repeat tasks they had done previously taking into account what they had learned about argumentation in the interim. The case library was added during their third argument-making activity, when it was appropriate to introduce into argumentation the generation of issues and the gathering of evidence.

\subsection{Tasks}

Students began by seeing a movie enacting an historical debate uncovering arguments between thinkers such as Aristotle and Democritus over whether a vacuum exists and then made their own arguments for or against; continued by considering an ethical dilemma, how to deal with a good friend who is stealing things; and then moved on to consider a multi-faceted dilemma, how to deal with the road congestion in Israel -- should the proposed toll highway be built or not? The first activity built on work they had already done in science and modeled argumentation; the second asked them to cull evidence for their assertions from their own experiences; the third asked them to consider an issue with more facets and required them to gather and use new knowledge in order to derive assertions and provide evidence. Collaborative groups remained the same across each activity.

Each activity was multiphased: it was initiated by a phase of engagement and understanding; then was a phase of argument creation; then sharing of arguments and further argument synthesis in a classroom forum; construction of a presentation; and presentation to the class. The first, third and fifth phases were carried out in a classroom forum, the others in small groups. Classroom forums allowed for sharing across groups, critiquing, and discussions on argumentation. Students experienced the same phases, rooted practice, tools, and kind of talk about practice across the different activities. Because two of the activities included in their engagement phase were arguments between experts that were reflected on and discussed in class, students had the opportunity to experience and analyze at least five arguments in the course of our experiment. 


\subsection{Software tools}

Students used two software tools in addition to the case library. We hypothesized that collaboration would be enhanced by providing tools to concretely specify controversies, assertions, and evidence, that would allow them to manipulate their ideas and the relationships of those ideas to each other in a shared and visual space, and that would help them propose issues to concentrate on and evidence for each while they were working together. Software tools were introduced as needed, and significant class time was spent helping students learn to use the programs and, in addition, helping them understand how each was relevant to their task. The first tool, based on the argument map constructed by Lesgold and his colleagues (Cavalli-Sforza, Lesgold, Weiner, 1992), allowed students to outline arguments and represent the relationships between assertions and evidence. Students used Astound, a presentation program, to make a multimedia presentation of their argument for others. The two tools were linked.

\subsection{Teacher's role:}

The teacher's role was to control the fulfillment of the five stages of each activity and to establish the vocabulary of argumentation. Her interventions with kids working/learning in small groups were to focus on "understanding what's the point", "how do you know this?" or "do you think this will convince people?". During class discussions, the teacher presented and analyzed interim verbal reports about arguments by each group and established practices and norms for argumentation.

\section{Arguing with the Case Library in the Classroom}

The curriculum was implemented in a Grade 9 group of students belonging to the $60 \%$ upper high level of reading/writing population as the second part of a yearly course on literacy. The first part was devoted to computer literacy -- mastery of computer tools, including all the tools necessary in for the argumentation curriculum except the case library. There were sixteen students organized into four groups. We focused on a group of three students, watching them closely and recording them on video so as to be able to go back and analyze what they were doing. We chose the group we knew to be the most articulate for that analysis. We also looked in on the other groups to get a sense of what they were doing, recording notes as we watched. Our analysis is based on three sessions using the tool.

While our data set is small and our analysis is therefore quite preliminary, some interesting suggestions emerge. Our case library indeed invited the best students (the group we were tracking) to interpret and helped them create good arguments. It seemed, as well, to help these students to acquire new norms about argumentation. Together, these suggest that case libraries with design like ours hold promise for scaffolding argumentation and the learning of argumentation skills. Use of the case library also seemed to support conflict resolution and negotiation among collaborating students, suggesting the potential of case libraries of this kind as collaboration tools. Focusing on how other groups used the case library, we also noticed some shortcomings, and when we look at what differentiates the more successful group from the others, our analysis points out some prerequisite skills needed for the case library to play the powerful role it played for our focal group.

\subsection{Setting the scene: The case library helps with construction of an argument}

An early encounter with the case library by the group of three students we were watching $(\mathrm{C}, \mathrm{M}$, and $\mathrm{O}$ ) was very exciting to us. Students had been through two argumentation construction exercises before they began work on the road, so they already had some idea about what an argument was and how to construct one. All three students were against construction of the road, but for different reasons. One student, C, brought bias to the situation. She was against construction of the road because of its environmental impact; her focus on the environment blinded her to other reasons for building or not building the road. The two other students wanted to make sure that the group's argument was more multi-faceted and that it considered several pros and cons. Using the case library as a tool, they are able to put together a good multi-faceted argument, help $\mathrm{C}$ to see some other facets as well, and help $\mathrm{C}$ to extend her understanding of what a good argument is.

Leaving aside social and other issues and focusing only on how these students used the case library itself, we can see how the case library's structure and content helped them put a good argument together. They began by browsing the table of contents to see what they could find. Since they were against the road and had chosen air pollution as their perspective, they looked at the list of issues to see stories about air pollution resulting from increased roads. Together, they read the cases, summed up their ideas, and wrote them in a file. Any texts that helped them make an argument against the road were selected and marked. They began by ignoring other issues, e.g., economics, but as they read and discovered that it was an important factor in several of the pollution stories, they progressively brought it and other issues into consideration, integrating what they found in stories into their argument maps and marking stories that provided good evidence. They constructed their argument by 
choosing several cases that supported it, summing them up, and integrating them into a text.

\subsection{Supporting conflict resolution and negotiation}

The case library also supported the students as they negotiated a conflict. $\mathrm{C}$ wanted to focus on pollution. $\mathrm{M}$ wanted to focus farther. Using the list of issues as his ammunition, $\mathrm{M}$ first showed $\mathrm{C}$ how many more issues there were; then using stories themselves as ammunition, he showed her how a larger constellation of issues was related to their main perspective, pollution, than she had originally thought. The cases not only provided evidence for constructing arguments (their assignment); they also provided evidence that students used to argue and negotiate issues among themselves. The lists of issues and alternative solutions provided evidence as well. The on-screen lists of alternative solution types and issues helped some students grasp the breadth of the domain; they were able to use those lists to help others gain a similar understanding.

\section{3 "What is evidence?" Acquiring new norms about what makes a good argument}

We expected the case library to help in creating an argument and for its cases to be cited as evidence, and indeed this group used it that way, as did all of the other groups in the class. But in addition to making an argument, the group we were watching also used the case library to increase their understanding of what a good argument is. O persisted in challenging the argument put together so far by looking for evidence against it. That helped her to find more evidence for it. She worked towards understanding what will happen if the road is built. Her conclusion: more roads means more cars and more traffic jams. She also persisted in enhancing the argument against the road by supporting alternative solutions, adding to the argument by arguing for an alternative to the road. Her conclusion there: Israel is losing a golden opportunity to develop alternative means of transportation. In essence, $\mathrm{O}$ articulated what $\mathrm{C}$ meant and was not able to say herself.

$\mathrm{O}$ worked by herself, so the acquisition of a new argumentative norm by the group might be questionable. However, the availability of the information allowed $\mathrm{O}$ and $\mathrm{M}$ to see how better arguments could be formulated, and they passed that on to C. Like in Roschelle (1992) and Schwarz (1997), the group functioned as a single entity. It finally reached agreement through joint construction of a presentation. The case library was a resource and an organizer of the domain that suggested ways of arguing.

\subsection{Shortcomings}

But all was not perfect. The group we watched was clearly the most able in the class. They were more articulate and had the most developed social skills. Other groups were not as successful constructing arguments. They used the case library to find evidence for or against the road, but they stopped there; they didn't do the sophisticated exploration of the stories that our focal group did, nor did the lists of issues and alternative solutions help them broaden their outlooks sufficiently. We don't know, because we did not collect detailed data on them, whether use of the case library increased their ability to argue or not. Second, even in the exemplary group we followed, we felt that there was too much mirroring of the structure of the case library in their presentations. They sometimes took text verbatim from stories and preserved links between stories without integrating it all better into a coherent argument.

Together, these shortcomings suggest the need for more large-group discussion and evaluation of incrementally-developed arguments, providing multiple iterations within the same activity, feedback from outside the small groups, and additional reflection on argumentation strategies and good arguments.

\subsection{Necessary prerequisites}

We believe that the group we watched did better than others at using the case library at least partially because of the excellent collaboration skills and attitude about learning. They understood well the need to divide work, strategies for dealing with conflict, how to integrate ideas, and so on. The case library provided them with evidence they needed in order to implement these strategies. As well, this group had mastered the other two tools before beginning work with the case library. Some groups were still grappling with using the other two pieces of software when the case library was made available to them. Clearly, the environment was a complex one. On the other hand, that we observed the case library as so useful for one group of students gives us hope that with better curriculum design, more integrated software tools, and a culture of collaboration and knowledge building already instilled in classrooms, case libraries designed as invitations to interpret will be powerful tools for collaborative learning of how to reason. 


\section{References}

Cavalli-Sforza, V., Lesgold, A.M., Weiner, A.W. (1992). Strategies for contributing to collaborative arguments. Proceedings of the 14th Annual Conference of the Cognitive Science Society, 755-760. Hillsdale, N.J: LEA.

Collins, A., Brown, J.S., Newman, S.E. (1989). Cognitive apprenticeship: Teaching the crafts of reading, writing, and mathematics. In L. B. Resnick (Ed.), Knowing, learning, and instruction: Essays in honor of Robert Glaser (pp. 453-94). Hillsdale, N.J: Lawrence Erlbaum Associates.

Domeshek, E., and Kolodner, J. (1992). Towards a case-based aid for conceptual design. International Journal of Expert Systems, 4(2):201--220.

Ferguson, W., Bareiss, R., Birnbaum, L. \& Osgood, R. (1992). ASK systems: An approach to the realization of story-based teachers. Journal of the Learning Sciences 2: 95-134.

Kolodner, J. (1993). Case-Based Reasoning. S an Mateo, CA: Morgan Kaufmann.

Kolodner, Janet L. (1997). Educational Implications of Analogy: A View from Case-Based Reasoning. American Psychologist.

Means, M. L. \& Voss, J. F. (1996). Who reasons well? Two studies of informal reasoning among children of different grade, ability and knowledge levels. Cognition and Instruction, 14, 139-178.

Narayanan, N. H., Hmelo, C.E., Petrushin, V., Newstetter, W. Guzdial, M., \& Kolodner, J.L. (1995). Computer support for collaborative learning through generative problems, CSCL Proceedings, 95, ACM Press, (247-254).
Roschelle, J. (1992). Learning by collaboration: convergent conceptual change. The Journal of the Learning Sciences, 3, 235-276.

Schwarz, B. B. (1997). Understanding symbols with intermediate abstractions: An analysis of the collaborative construction of mathematical meaning. In C. Pontecorvo, R. Säljö \& L. B. Resnick (Eds.), Tools, Discourse, and Reasoning, NATO series, Lucca.

Voss, J., Perkins, D. \& Segal, J. (Eds.), Informal Reasoning and Education. Hillsdale, N.J.:LEA.

Yackel, E. \& Cobb, P., (1996), Sociomathematical norms, argumentation, and autonomy in mathematics. Journal for Research in Mathematics Education, 27(4), 458-477.

\section{Acknowledgments}

The research reported here was supported by the Woodruff Foundation and the ARPA CAETI program under contract N66001-95-C-8608. The work was done while Kolodner was a Visiting Professor in Hebrew University's Department of Computer Science and School of Education.

\section{Author's Addresses}

Janet L. Kolodner: Edutech Institute, Georgia Institute of Technology, GCATT Building, 250 14th Street, N.W. Suite \#138, Atlanta, GA 30318-0490. jlk@cc.gatech.edu.

Baruch Schwarz, Reuma DeGroot Barkai, Edith LevyNeumand, Anna Tcherni, Anat Turbovsky: School of Education, Mount Scopus Campus, Hebrew

University, Jerusalem, ISRAEL. msschwar@pluto.mssc.huji.ac.il 